\title{
Foreign body: A sewing needle migrating from the gastrointestinal tract to pancreas
}

Fatih Dal @

$\begin{array}{ll}\text { ABSTRACT } & \text { Of all ingested foreign bodies, } 2.4 \% \text { comprise of sewing needles. Through perforation of gastrointestinal } \\ \text { tract, which occurs in } 1 \% \text { of cases, they can migrate into the liver and pancreas. Foreign bodies in pancreas } \\ \text { should be considered in the differential diagnosis of chronic abdominal pain. Computed tomography scans } \\ \text { provide valuable information for the localization of the lesion, which guide the surgeon during the opera- } \\ \text { tion. Secondary to foreign bodies that migrate to the pancreas, complications with high mortality such as } \\ \text { pancreatitis, pseudoaneurysm, and pancreas abscess can be seen. Thus, for this patient group, diagnostic } \\ \text { laparoscopy is recommended, considering its advantages of decreased postoperative pain, decreased wound } \\ \text { infection, and faster recovery time. Here we present a case of a 23-year-old female patient, from whom an } \\ \text { ingested needle that migrated from the back wall of the stomach to the pancreas was extracted by laparos- } \\ \text { copic surgery. } \\ \text { Keywords: Sewing needle, pancreas, laparoscopy }\end{array}$

ORCID ID of the author: F.D. 0000-0002-9768-8125

Cite this paper as:

Dal F, Hatipoğlu E, Teksöz S, Ertem M. Foreign body: A sewing needle migrating from the gastrointestinal tract to pancreas. Turk J Surg 201834 (3): $256-258$

Department of General Surgery, İstanbul University Cerrahpaşa School of Medicine, İstanbul, Turkey

Corresponding Author Serkan Teksöz

e-mail: serkanteksoz@gmail.com

Received: 06.10 .2015

Accepted: 3.12.2015

Available Online Date: 03.01.2018

CCopyright 2018

by Turkish Surgical Association

Available online at

www.turkjsurg.com

\section{INTRODUCTION}

Out of all the ingested foreign bodies, $43.7 \%$ are organic, $56.3 \%$ are inorganic, and $2.4 \%$ are sewing needles. Most of the ingested foreign bodies are excreted spontaneously (1). These foreign bodies may reach pancreas and liver in $1 \%$ of patients, through penetration of small intestine or stomach wall $(1,2)$. Foreign bodies in pancreas might cause serious complications such as pancreatitis, pancreatic abscess, and pseudoaneurysm. These should be removed either endoscopically or surgically $(1,3,4)$. In few cases, foreign bodies can also be removed using open surgical techniques $(2,5)$. However, the suggested technique is the laparoscopic approach before open surgery $(3,6,7)$. Here we report the case of a 23-year-old female patient, who presented with epigastric pain and a sewing needle was removed laparoscopically from her pancreas parenchyma.

\section{CASE PRESENTATION}

A 23-year-old female patient presented with epigastric pain and retrosternal burns that continued intermittently for seven years. She had used proton pump inhibitors (PPI) and as her symptoms did not resolve, she presented to the hospital. In her physical examination, there was minimal tenderness and discomfort in the epigastric area without rebound sign or defense. Laboratory blood tests including her hemogram, biochemical markers, liver function tests, kidney function tests, and amylase levels were within normal limits. Her standing abdominal x-ray was also normal (Figure 1a). During gastroscopy, no sign of any pathology related to a foreign body was observed. We performed a barium follow-through $x$-ray with an initial diagnosis of gastroesophageal reflux disease, and in this test, we observed a foreign body in the epigastric area (Figure 1b). When patient's medical history was questioned again, it was found that she had accidentally swallowed a sewing needle seven years ago. She underwent computed tomography screening and we saw that a foreign body was present starting from the posterior side of the stomach reaching head and body of the pancreas. (Figure 2a) The patient was hospitalized, obtained the written informed consent for publication and prepared for operation, undergoing the whole routine preoperative workup. She underwent a laparoscopic surgery. During the laparoscopic exploration, the gastrocolic ligament was opened with the help of a laparoscopic instrument (Ligasure ${ }^{\mathrm{TM}}$; Vessel Sealing System, Covidien, MA, USA). Foreign metallic body (sewing needle), spanning from the posterior of a small curvature of stomach to the head and body of pancreas was visualized. (Figure $2 b$ ) Using a laparoscopic instrument (Endo clinch $^{\mathrm{TM}}$; single-use instrument, Covidien, MA, USA), the needle was $(4 \mathrm{~cm})$ removed from the abdomen in three pieces. (Figure 3a) The defect in the stomach wall was repaired laparoscopically using 3/0 vicryl sutures. The patient did not have any postoperative bleeding and she was mobilized $16 \mathrm{~h}$ postoperatively. She was started on oral diet on postoperative day four. She was discharged on postoperative day six. During her hospitalization, there was no wound infection or dehiscence (Figure 3b). 


\section{DISCUSSION}

Most of the foreign bodies such as fishbone, tooth, sewing needle, and chicken bone that are accidentally swallowed, are excreted spontaneously through anus. Only $1 \%$ of these penetrate the gastrointestinal tract $(1,2)$.Common perforation sites are crycopharyngeal ring, cardia, phylorus, C-loop duodenum, ligament of Treitz, Meckel diverticulum, ileocecal valve, appendix, and rectosigmoid junction (1-3). In some cases, these sharp foreign bodies can perforate the walls of stomach or duodenum and reach the liver. Foreign bodies reaching pancreas
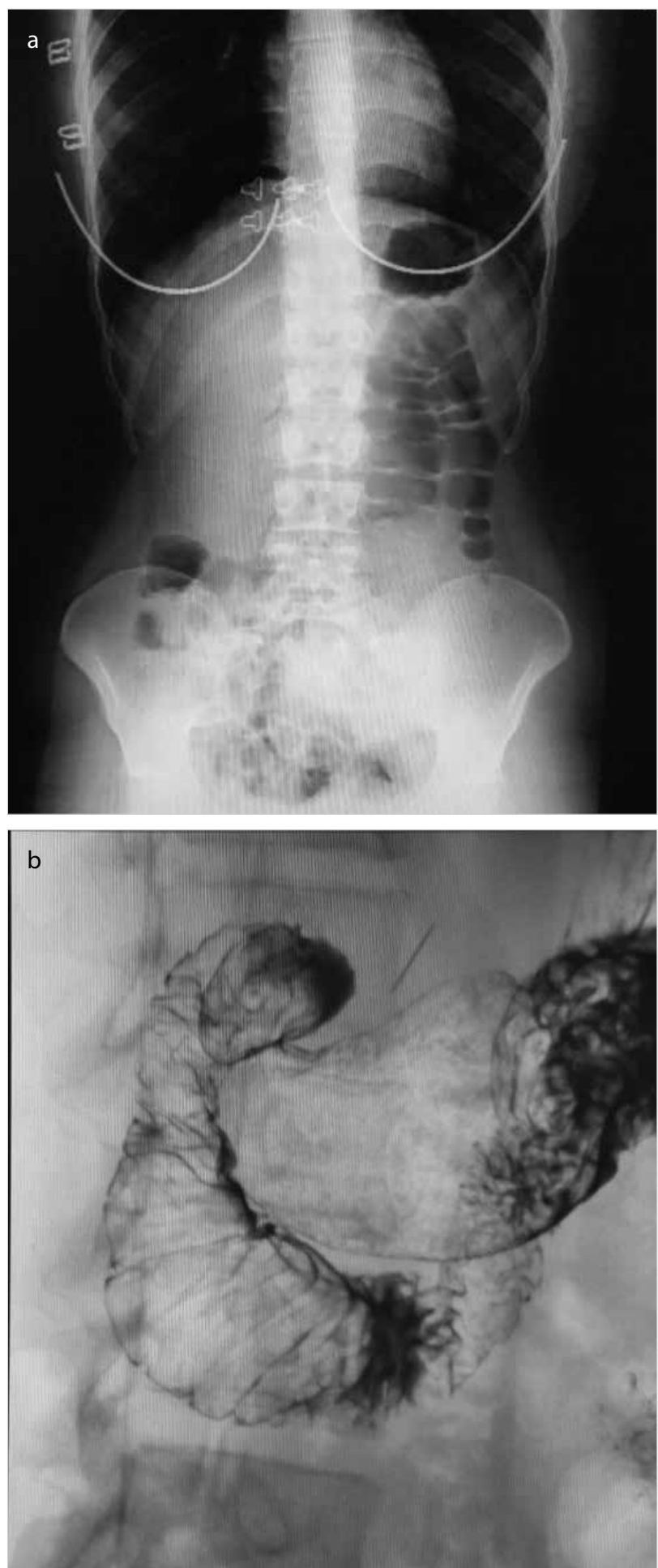

Figure 1. a, b. (a) Normal standing $x$-ray and (b) stomach passage $x$-ray and foreign body
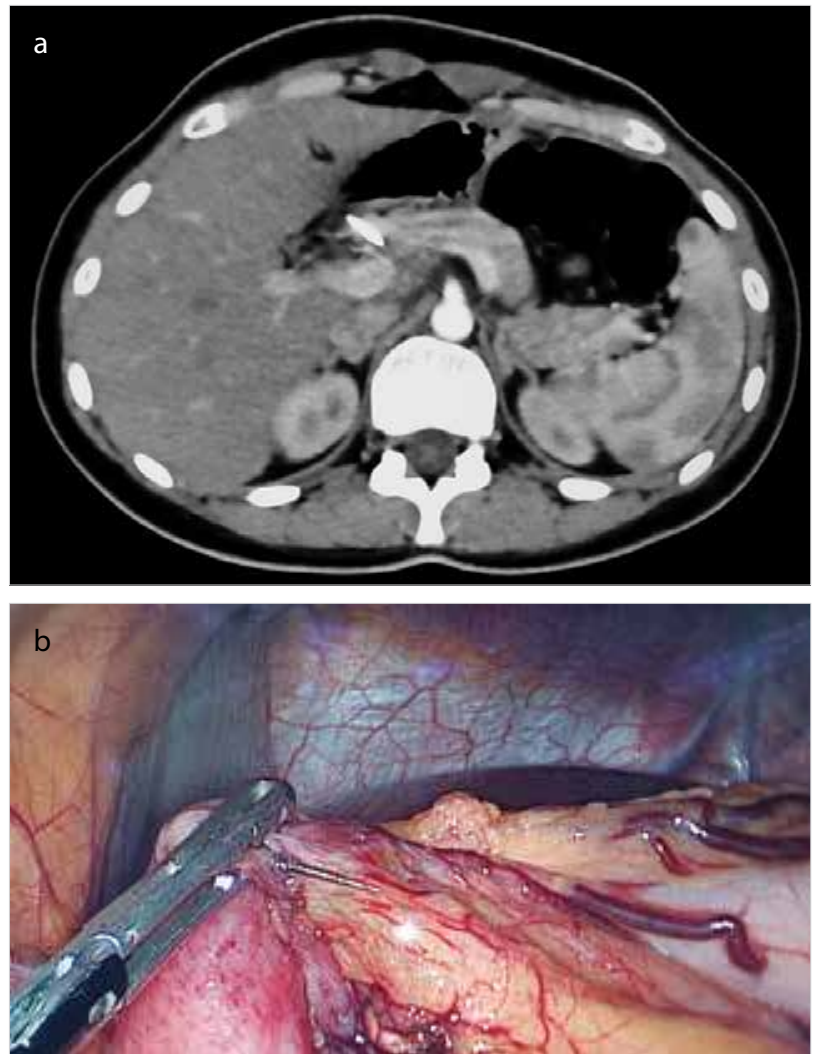

Figure 2. a, b. (a) Abdominal CT and (b) metallic foreign body
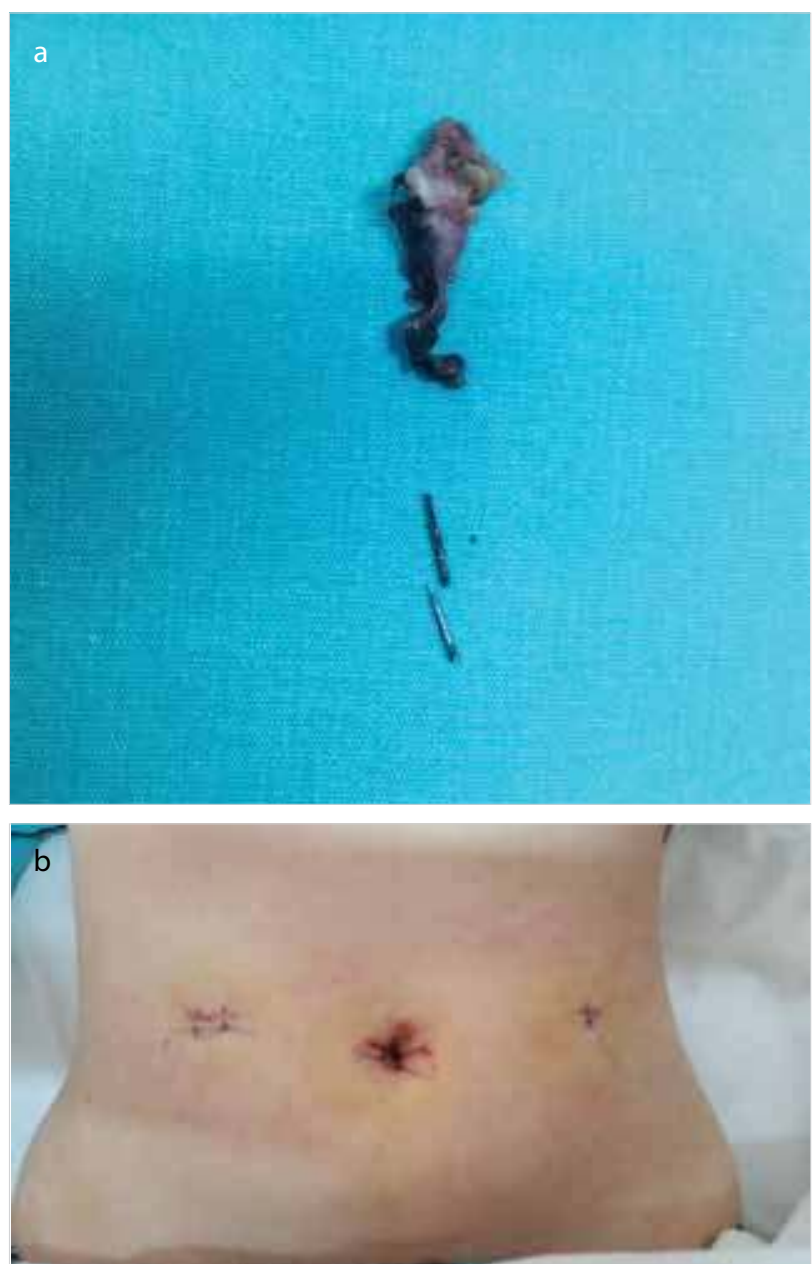

Figure 3. a, b. (a) Metallic foreign body and (b) postoperative day four 
and liver parenchyma can cause abscess, pseudoaneurysm, pancreatitis, and high-mortality-risk complications $(1,4,5)$.

Most patients cannot remember any accidental swallowing of foreign bodies. Therefore, diagnosis of these patients is not easy. Symptoms can mimic other diseases such as gastroesophageal reflux and gastritis, just like in our patient. Standing $x$-rays are used widely for diagnosis of foreign bodies in the abdominal area but may not provide exact localization like abdominal CT (3). Our patient presented to us with chronic abdominal pain with no mention of any foreign body ingestion seven years ago. Therefore, foreign body ingestion was not included in our initial diagnosis. We did not perform a doublesided standing abdominal x-ray, and one-sided standing abdominal x-ray did not reveal the sewing needle due to superposition. We believe that the first diagnostic test to perform, in patients with foreign body ingestion, should be a doublesided standing abdominal x-ray. Abdominal CT plays an important role in the diagnosis, localization, and determination of the surgical procedure in complicated cases comprising $1 \%$ of all patients.

Although open surgical approach is widely used for diagnosed abdominal foreign body extraction, in the modern surgical platforms, laparoscopic approach is advocated in stable nonacute patients due to its advantages of less postoperative pain, lower incidence of wound infection, and minimal surgical stress, in turn improving wound healing $(2,5,8)$. We found three cases of extraction of foreign body from the pancreas in literature, and here we present the fourth case $(3,6,7,9)$.

\section{CONCLUSION}

In stable patients with chronic abdominal pain, foreign bodies migrated into the abdominal cavity should be kept in mind for differential diagnosis and they should be questioned regarding this in the medical history. Abdominal CT presents an important advantage for both localization and decision of surgical approach. The treatment of such foreign bodies is surgical due to high-mortality-risk complications. Laparoscopic minimally invasive surgery should be preferred to open surgery due to advantages of better diagnosis, less postoperative pain, less wound infection, and faster recovery times.
Informed Consent: Written informed consent was obtained from patient who participated in this study.

Peer-review: Externally peer-reviewed.

Author Contributions: Concept - M.E., S.T.; Design - S.T., F.D.; Supervision - M.E., S.T.; Resource - E.H., F.D.; Materials - E.H., F.D.; Data Collection and/or Processing - E.H., F.D.; Analysis and/or Interpretation - M.E., S.T.; Literature Search - S.T., F.D.; Writing Manuscript - S.T., F.D.; Critical Reviews - S.T., F.D.

Conflict of Interest: The authors have no conflicts of interest to declare.

Financial Disclosure: The authors declared that this study has received no financial support.

\section{REFERENCES}

1. Barros JL, Cabellero AJ, Rueda JC, Monturiol JM. Foreign body ingestion: Management of 167 cases. World J Surg 1991; 15: 783788. [CrossRef]

2. Toyonaga T, Shinohara M, Miyatake E, Ouchida K, Shirota T, Ogawa T, et al. Penetration of the duodenum by an ingested needle with migration to the pancreas: Report of a case. Surg Today 2001; 31: 68-71. [CrossRef]

3. Jain A, Nag HH, Goel N, Gupta N, Aganval AK. Laparoscopic removal of a needle from the pancreas. J Minim Access Surg 2013; 9: 80-81. [CrossRef]

4. Goh BK, Yong WS, Yeo AW. Pancreatic and hepatic abscess secondary to fish bone perforation of the duodenum. Dig Dis Sci 2005; 50: 1103-1106. [CrossRef]

5. Yasuda T, Kawamura S, Shimada E, Okumura S. Fish bone penetration of duodenum extending into the pancreas: report of a case. Surg Today 2010; 40: 676-678. [CrossRef]

6. Wu C, Hungness ES. Laparoscopic removal of a pancreatic foreign body. JSLS. 2006; 10: 541-543.

7. Cheah WK, Mar Fan MJ, Goh PMY. Laparoscopic removal of fish bone. Surg Laparosc Endosc Percutan Tech 1999; 9: 223-225. [CrossRef]

8. Yadav TD, Singh H, Sah R. Unusual foreign body of pancreas: surgical management. JOP 2013; 14: 669-670.

9. Aarabi S, Stephenson J, Christie DL, Javid PJ. Noningested intraperitoneal foreign body causing chronic abdominal pain: a role for laparoscopy in the diagnosis. J Pediatr Surg 2012; 47: e1517.[CrossRef] 